\title{
Performance Evaluation to Explore the Effectiveness of Training Programs among the Wheat Growers of Tehsil Nankana Sahib
}

\author{
Safdar Ali, Muhammad Iftikhar*, Ghazanfar Ali Khan and Muhammad Hammad Raza
}

Institute of Agricultural Extension and Rural Development, University of Agriculture, Faisalabad, Pakistan

\begin{abstract}
Wheat is an essential part of meal from poor to rich families. However, comparing its neighboring countries, Pakistan could not perform impressively in the production of wheat. Lack of knowledge on the part of farmers about land preparation, irrigation application, pest and disease control and fertilizer application were the major hindering factor to meet the potential yield of wheat. Therefore, public and private sector provided many training programmes to enhance wheat production. The present study was conducted in tehsil Nankana Sahib. A sample of 110 respondents was taken conveniently who had received different trainings regarding wheat production. The collected data was analyzed with the help of Statistical Package for Social Sciences (SPSS) to derive conclusions and formulate recommendations. Majority of the respondents (74\%) reported that their knowledge and skills had improved after getting training about the production technology of the wheat crop. There should be adequate material and well-trained extension field staff to educate the farmer.
\end{abstract}

Keywords: Social; Population; Agriculture; Irrigation; Income

\section{Introduction}

Pakistan is known as an agricultural country. Greater than $70 \%$ population of Pakistan is related to agriculture. Now agriculture contributes 20.9 percent to GDP (Gross Domestic Product). It also provides raw material for industry (Govt, 2017). The lack of technical knowledge about production technology of the major crops could be an important one. In this situation extension can play an important role for the increase of per hectare yield of different crops. It is the responsibility of the extension worker to diffuse the innovation among the farmer community. For achieving this goal, various extension strategies have been applied which aimed at increasing from productivity and improving the income [1].

It has been observed due to the unawareness about the improved cropping technologies among farmers in Pakistan results the low yield. There are various information diffusion methods has been adopted by public and private extension staff in Pakistan, but now it's needing to manage well-developed and well-planned training strategies [2]. The usefulness training based on the theoretical aspect that the trainee can describe and able to apply it in the actual environment, learned in a training program. The farmers are willing to gain training in the field of new agricultural practices and modern techniques they want to get training to uplift their living standard [3].

Updated international and local market information is the need of the time. This kind of information has direct influence on the production of wheat crop. Growers are seeking for this kind of useful information, training and exhibitions are the most likely useful events for getting latest information [4]. Training is considering as the most reliable source for the farmers due to that they can make their decisions in more efficient manners Training and development are the continuous process [5]. The need is that to perform one's duty efficiently. It is helpful to acquire new knowledge, experience, skill and techniques to perform effectively. There is need to know how to lead others are the better reasons for the training and development [6].

It is necessary to enhance the wheat production either by increasing its area under cultivation or by using improved production technologies. Better and latest production practice is a most important factor for the better wheat production [7].
Dissemination of the technical knowledge is not easy by itself. There is need of extension education and different extension methods used to technology transfer in agriculture sector. The extension training programs are the tools to improve the agricultural techniques. The extension training programs creates opportunities to establish relationship between farmers and extension workers. The extension method based on the aim and experience it is most effective, beneficial and fundamental knowledge to improve the crop production [8]. It is very important to strengthen the farmers, extension staff and research relationship [1]

Sufficient training of famers about sustainable insect and pest control is needed urgently to minimize the risk of low yield. These pesticides also produce some lethal substances from which many greenhouse gas emissions arise, thus polluting our environment badly and having negative impacts on vegetation and bio-diversity, ultimately causing the climatic change [9]. The provision of training about the production technology merely is not the solution of all the problems faced by the farming community but the contribution to increase the farm productivity. The effectiveness of farmers' training in the developing countries showed that many programs were failed in the beginning after their initiation because of concentrating on a specific technology transfer rather than empowering them including knowledge dissemination [10].

\section{Methodology}

The study was conducted in tehsil Nankana Sahib, in the Punjab, Pakistan. A sample of 110 respondents was selected purposively, who

*Corresponding author: Muhammad Ifikthar, Institute of Agricultural Extension and Rural Development, University of Agriculture, Faisalabad, Pakistan, Tel +92 41 9200161; E-mail: agrigak444@yahoo.com

Received December 07, 2017; Accepted January 03, 2018; Published January 10, 2018

Citation: Ali S, Iftikhar M, Khan GA, Raza MH (2018) Performance Evaluation to Explore the Effectiveness of Training Programs among the Wheat Growers of Tehsil Nankana Sahib. Arts Social Sci J 9: 321. doi: 10.4172/2151-6200.1000321

Copyright: (c) 2018 Ali S, et al. This is an open-access article distributed under the terms of the Creative Commons Attribution License, which permits unrestricted use, distribution, and reproduction in any medium, provided the original author and source are credited. 
Citation: Ali S, Iftikhar M, Khan GA, Raza MH (2018) Performance Evaluation to Explore the Effectiveness of Training Programs among the Wheat Growers of Tehsil Nankana Sahib. Arts Social Sci J 9: 321. doi: 10.4172/2151-6200.1000321

Page 2 of 3

had received different trainings regarding wheat crop.

\section{Results and Discussion}

\section{Knowledge and skill gained by farmers after training}

The role of the extension worker is very important in uplifting the living standard and the knowledge of the farmer. The inappropriate and inefficient work of the extension worker leads to the failure of the extension and dissemination process [11].

The data shown in the Table 1 stated that majority (40.90\%) of the respondents was familiar with the extension field staff both by name and face. The reason is that the fields of the farmers are on the way of the extension worker. Some of the farmers have personal relation with the extension worker. These results showed that most of the respondents were familiar with the extension field staff both by name and face.

The data presented in Table 2 depict that $50 \%$ of the respondents could select the land very easily and they knew about the selection of the land for the wheat crop. They attend the training session organized by the extension field staff. There was a clear majority (80.9\%) of the respondents who had very high level of information and skill regarding the land preparation. A large majority (60.9\%) of the respondents had very high level of knowledge and skill regarding the crop rotation. There were good numbers $(46.36 \%)$ of the respondents which can select the

\begin{tabular}{|l|c|c|}
\hline Known as & Frequency & Percentage \\
\hline By face & 35 & 31.82 \\
\hline By name & 30 & 27.27 \\
\hline Both by face and Name & 45 & 40.90 \\
\hline Total & 110 & 100 \\
\hline
\end{tabular}

Table 1: Distribution of the respondents according to the types of awareness about the extension personnel in their area. very good quality of seed. Majority (57.3\%) of the respondents had high level of knowledge and skill for the seed rate.

The table also depict that there were a huge number (66.4\%) of the respondents had very high level of knowledge and skill regarding the fertilizer applications, $(20 \%)$ of the respondents had good command on the fertilizer application, (6.4\%) of the respondents had medium and (7.3\%) of the respondents had very poor level of skill and knowledge regarding fertilizers application. The table depict that a huge majority (70\%) of the respondents had very high level of knowledge and skill regarding weed management, $(12.7 \%)$ of the respondents had good command on the weed management.

The data given in Table 2 reveal that a majority (55.5\%) of the respondents who had good command on the skill and knowledge about the no. of irrigation for the wheat crop. According to the results of the above table there were large majority (70\%) of the respondents who had very high level of command on irrigation time, the $(20 \%)$ of the respondents had good level of skill and knowledge regarding the irrigation time the remaining (3.6\%) had medium level of skill and knowledge regarding the irrigation methods. The respondents displayed in the Table 2 were attending the training session arranged by the extension field staff. The respondents who were actively taking part in the training activities had high level of information.

The data presented in the Table 3 showed that all the respondents replied that there had been improvement in their knowledge, skill, attitude, yield social status and other field of field practices regarding the wheat production. Majority of the respondents (74\%) reported that their knowledge and skill had improved after getting training about the production technology of the wheat crop. Majority (73.6\%) of the respondents reported that they started to produce quality produce after participating in the training programs. A large majority $(73.6 \%)$ of the respondents reported that there was improvement in their social

\begin{tabular}{|c|c|c|c|c|c|c|c|c|c|c|}
\hline \multirow{3}{*}{$\begin{array}{l}\text { Knowledge and skills } \\
\text { concerning different } \\
\text { production practices after } \\
\text { trainings }\end{array}$} & \multicolumn{10}{|c|}{ Level of knowledge and skill gained } \\
\hline & \multicolumn{2}{|c|}{ Very High } & \multicolumn{2}{|c|}{ High } & \multicolumn{2}{|c|}{ Medium } & \multicolumn{2}{|c|}{ Low } & \multicolumn{2}{|c|}{ Very Low } \\
\hline & f & $\%$ & f & $\%$ & $\mathbf{f}$ & $\%$ & f & $\%$ & f & $\%$ \\
\hline Land Selection & 56 & 50.9 & 4 & 3.6 & 14 & 12.7 & 12 & 10.9 & 22 & 20 \\
\hline Land Preparation & 89 & 80.9 & 5 & 4.5 & 6 & 5.4 & - & - & 10 & 9.09 \\
\hline Crop Rotation & 67 & 60.90 & 16 & 14.5 & 15 & 13.63 & - & - & 12 & 10.90 \\
\hline Seed selection & 51 & 46.36 & 22 & 20 & 17 & 15.45 & 8 & 7.2 & 10 & 9.09 \\
\hline Seed Treatment & 47 & 42.7 & 22 & 20 & 26 & 23.6 & 3 & 2.7 & 12 & 10.9 \\
\hline Sowing Methods & 74 & 67.3 & 12 & 10.9 & 11 & 10 & 4 & 3.6 & 9 & 8.00 \\
\hline Seed Rate & 63 & 57.3 & 12 & 10.9 & 17 & 15.5 & 4 & 3.6 & 14 & 12.7 \\
\hline Row Spacing & 60 & 54.5 & 24 & 21.8 & 2 & 1.8 & 9 & 8.2 & 15 & 13.6 \\
\hline Plant Spacing & 78 & 70.9 & 31 & 28.2 & 1 & 0.9 & - & - & - & - \\
\hline Sowing Time & 68 & 61.8 & 7 & 6.4 & 17 & 15.5 & 13 & 4.5 & 5 & 11.8 \\
\hline Fertilizer Application & 73 & 66.4 & 22 & 20.0 & 78 & 6.4 & - & - & 8 & 7.3 \\
\hline Weed Management & 77 & 70.0 & 14 & 12.7 & 6 & 5.5 & 1 & 0.9 & 12 & 10.9 \\
\hline Disease control Methods & 61 & 55.5 & 18 & 16.4 & 15 & 13.6 & 6 & 5.5 & 10 & 9.1 \\
\hline Insect Pest Control Methods & 58 & 52.7 & 25 & 22.7 & 6 & 5.5 & 13 & 11.8 & 8 & 7.3 \\
\hline No. of Irrigations & 61 & 55.5 & 17 & 15.5 & 14 & 12.7 & 6 & 5.5 & 12 & 10.9 \\
\hline Irrigation Methods & 81 & 73.6 & 18 & 14.4 & 4 & 3.6 & - & - & 7 & 4.4 \\
\hline Irrigation Time & 78 & 70.9 & 22 & 20.0 & 4 & 3.6 & 2 & 1.8 & 4 & 3.3 \\
\hline Weather Conditions & 77 & 70.0 & 23 & 20.9 & 3 & 2.7 & 1 & 0.9 & 6 & 5.5 \\
\hline Harvesting Time & 83 & 75.4 & 24 & 21.8 & 2 & 1.8 & 1 & 0.90 & - & - \\
\hline Harvesting Methods & 67 & 60.90 & 16 & 14.5 & 15 & 13.6 & 6 & 5.4 & 6 & 5.4 \\
\hline Storage & 72 & 65.45 & 26 & 23.6 & 6 & 5.4 & - & - & 6 & 5.4 \\
\hline Transporting & 17 & 15.4 & 39 & 35.5 & 24 & 21.8 & 15 & 13.6 & 15 & 13.6 \\
\hline Marketing & 48 & 63.6 & 22 & 20 & 17 & 15.4 & 6 & 5.4 & 17 & 15.4 \\
\hline
\end{tabular}

Table 2: Distribution of the respondents according to their knowledge and skills gained after training with respect to different production practices. 
Citation: Ali S, Iftikhar M, Khan GA, Raza MH (2018) Performance Evaluation to Explore the Effectiveness of Training Programs among the Wheat Growers of Tehsil Nankana Sahib. Arts Social Sci J 9: 321. doi: 10.4172/2151-6200.1000321

Page 3 of 3

\begin{tabular}{|c|c|c|c|c|c|c|c|c|c|c|}
\hline \multirow[t]{2}{*}{ Improvement areas } & \multicolumn{2}{|c|}{ Very High } & \multicolumn{2}{|c|}{ High } & \multicolumn{2}{|c|}{ Medium } & \multicolumn{2}{|c|}{ Low } & \multicolumn{2}{|c|}{ Very Low } \\
\hline & f & $\%$ & f & $\%$ & $f$ & $\%$ & $f$ & $\%$ & f & $\%$ \\
\hline Knowledge level & 74 & 67.27 & 26 & 23.6 & 4 & 3.63 & - & - & 6 & 5.4 \\
\hline Attitude & 74 & 67.27 & 18 & 16.3 & 13 & 11.81 & 5 & 4.5 & - & - \\
\hline Knowledge about plants growth & 82 & 74.54 & 27 & 24.5 & 1 & 0.90 & - & - & - & - \\
\hline Crops outlook & 76 & 69.09 & 14 & 12.72 & 13 & 11.81 & 5 & 4.5 & - & - \\
\hline Current Problems & 83 & 75.45 & 24 & 21.81 & 3 & 2.72 & - & - & - & - \\
\hline Field Management Issues & 73 & 66.3 & 16 & 14.5 & 14 & 12.7 & 5 & 4.5 & 2 & 1.8 \\
\hline Quality of produce & 81 & 73.6 & 26 & 23.6 & 3 & 2.72 & - & - & - & - \\
\hline Income from wheat crop & 83 & 75.4 & 24 & 21.81 & - & - & 3 & 2.72 & - & - \\
\hline Area under wheat crop & 73 & 66.3 & 19 & 17.2 & 12 & 10.90 & 5 & 4.5 & 1 & 0.90 \\
\hline Social status & 81 & 73.6 & 25 & 22.7 & 2 & 1.8 & 2 & 1.8 & - & - \\
\hline Yield & 81 & 73.6 & 27 & 24.5 & 2 & 1.8 & - & 1.8 & - & - \\
\hline Cost/ benefit ratio & 70 & 63.6 & 27 & 24.5 & 10 & 9.09 & - & - & 3 & - \\
\hline Skill development & 76 & 69.09 & 15 & 13.6 & 12 & 10.9 & 7 & 6.3 & - & - \\
\hline
\end{tabular}

Table 3: Improvements by participating in the training sessions.

status after taking part in the training session. majority (69.09\%) of the respondents reported that there was significant improvement in the skill and knowledge after taking part in the training. A large majority $(75.5 \%)$ of the respondents reported that their income had been increased after taking part in training.

\section{Conclusions}

This research showed that training session have great importance in the farmers life because training is the good source for the improvement of farmers knowledge and skill level, further it is also responsible for the improving the farmers social and economic condition respectively.

\section{References}

1. Khatam A, Muhammad S, Chaudhry KM, Khan MZ, Gill IA, et al. (2013) Analysis of Farmer Field Schools as a tool of capacity building for resource poor farmers in Khyber Pakhtunkhwa. Pakistan Sarhad J Agric 1: 1-5.

2. Ahmad M, Jadoon MA, Ahmad I, Khan $H$ (2007) Impact of trainings imparted to enhance agricultural production in district. Mansehra Sarhad J Agric 4: 1-6.

3. Khan NP, Akhtar J (2006) Competitiveness and policy analysis of Potato production in different agro-ecological zones of northern areas: Implications for food security and poverty alleviation. The Pak Devel Review 4: 1137-1154.
4. Salam A (1986) Farm tractorization and productivity in Pakistan's Agriculture An analysis of farm level data. J of Agri Social Sciences 28: 131-144.

5. Farah AA (2006) An investigation into the adoption of recommended maize production practices by the farmers of tehsil Chiniot district Jhang MSc (Hons) Thesis Dept of Agri Ext Univ of Agri Faisalabad.

6. Agbarevo MNB (2013) Farmers' Perception of Effectiveness of Agricultura Extension Delivery in Cross-River State Nigeria. J Agric and Vet Sci 6: 1-7.

7. Kulkarni PP (2013) A Literature Review on Training and Development and Quality of Work Life Researchers World 2: 136-140.

8. Tesfaye T, Karippai V, Tesfaye T (2010) Farmers Training Effectiveness in Terms of Changges in Knowledge and Attitude: The Case of Holeta Melkassa and Debre Zeit Agricultural Research Centers Ethiopia. J of Agric Ext and R Dev 2: 89-96.

9. Blume BD, Ford JK, Baldwin TT, Huang JL (2010) Transfer of training: A metaanalytic review. Int J Manag Rev 36: 1065-1105.

10. Tripp RM, Wijeratne $V$, Piyadasa $\mathrm{H}$ (2005) What should we expect from farmer field schools A Sri Lanka case study. World Dev 10: 1705-1720.

11. Rahim F, Sadiq MS, Ibrahim M, Mehmmod Z (2003) Role of extension Agen in the diffusion of date palm cultivation in the District. Pangur (Balochistan) Sarhad J Agric 19: 595-602. 